\title{
Comparative Evaluation of Environmental Impact of Selected Ethoxylate Fatty Alcohols and Ethoxylate Fatty Acid Methyl Esters as Nonionic Surfactants
}

\author{
Iwona Szwach*, Marek Lukosek \\ Institute of Heavy Organic Synthesis “Blachownia”, Energetykow 9, 47-225 Kędzierzyn-Koźle, Poland
}

Received: 27 September 2016

Accepted: 14 December 2016

\begin{abstract}
This work presents a comparative ecological assessment of dodecanolethoxylates and rapeseed acid methyl ester ethoxylates as nonionic surfactants. It was found that ethoxylated rapeseed acid methyl esters show higher biodegradability and lower aquatic toxicity compared to 1-dodecanol ethoxylates. A prognostic model for environmental impact of the studied series of surfactants was developed using the data from biodegradation and aquatic toxicity tests combined with estimated concentration of the surfactants in a wastewater stream. It is shown that an ecological risk of bulk application of dodecanolethoxylates can be expected over a longer term, while significant reduction of environmental fate would occur by the alternative use of ethoxylated rapeseed acid methyl esters. We concluded that ethoxylated rapeseed acid methyl esters can be considered as environmentally superior surfactants.
\end{abstract}

Keywords: dodecanol, rapeseed methyl ester, ethoxylates, biodegradability, ecotoxicity

\section{Introduction}

Reduction of already existing pollution has a significant importance in the protection of the natural environment, particularly water ecosystems. However, many efforts are also focused on further regulations and actions to reduce the chemical load on the environment in the future [1]. Surfactants represent one of the widely used bulk chemicals with clearly increasing trends of production and fields of application $[2,5]$. In spite of their growing market, better environmental protection could be

*e-mail: szwach.i@icso.com.pl executed by gradual replacement of the existing surfactant types with their more environmentally friendly equivalents [3]. Therefore, the system of prognostic evaluation of environmental impact of chemicals is a convenient and valuable tool for assessing surfactants in this context to make decisions for strategic development and the creation of environmental policy, both on a company level and in state legislation [4].

Continuous technological progress results in the development of new surfactants, which gradually enter the market $[2,5]$. They are usually more efficient in performance, more environmentally friendly, or just utilise alternative raw materials. Among them, alkylpolyglycosides, sulfonated fatty acid methyl esters, or narrow-range distributed fatty alcohols can be 
encountered [6]. However, no surfactant has appeared in bulk production in more than 50 years, which could compete economically with soap, alkylbenzene sulfonates, or the conventional ethoxylated fatty alcohols [7]. The situation seems ti be able to change with the introduction of ethoxylated fatty acid methyl esters as replacements of ethoxylated fatty alcohols [8-9], which could be relatively cheaper and can by manufactured from such renewable resources as raw material at the same time [10]. Among them, rapeseed oil acid methyl esters were reported as a valuable and perspective alternative to the surfactants manufactured from other more expensive and less available plant oils $[11,14]$ or of petrochemical origin [12-13]. They already have proven to perform well in major applications as ingredients of cleaning and washing formulations [14-16].

Surfactants are important industrial products. The $\$ 60$ billion detergent market consumes up to 18 million tons of surfactants annually, including soaps [17]. After use, total amounts of surfactants are wasted and pollute the environment. Therefore, it is important to monitor and control their environmental fate [18]. The most important parameters of ecological evaluation of surfactants include biodegradability and toxicity against water organisms [19].

Available information on biodegradability and ecotoxicity of ethoxylated rapeseed acid methyl esters are very limited [20]. The aim of our work was a comparison of complex ecological evaluations of 1-dodecanol ethoxylates and rapeseed acid methyl ester ethoxylates as nonionic surfactants. For that purpose, data from their biodegradation and toxicity against water organisms were combined, taking into account the consumption of surfactants today to compare environmental fates in each case. Dodecanolethoxylates were selected as model representatives of the most commonly used fraction of ethoxylated fatty alcohols, while ethoxylated rapeseed acid methyl esters represented the emerging surfactant equivalents. The simulation assumed an alternative use of the compared surfactants in average amounts consumed on the market nowadays.

\section{Materials and Methods}

\section{Experimental}

\section{Chemicals}

Rapeseed oil acid methyl esters were supplied by Biodiesel Producers Association, Prague, Czech Republic, and responded to quality standard No. CSN 656507 , 1-Dodecanol, 98\% pure supplied by Sigma-Aldrich. Ethylene oxide was purchased from PKN Orlen, Płock, Poland, and $98.8 \%$ pure $\mathrm{NaOH}$ was purchased from Poland, the calcium catalyst containing organic calcium salts obtained by Blachowniain ICSO Kędzierzyn-Koźle (patent PL-360448).

\section{Ethoxylation of 1-Dodecanol and Fatty acid Methyl Esters (General Procedure)}

Ethoxylation reactions were carried out in a periodic pressure reactor with a capacity of $2 \mathrm{dm}^{3}$, made of stainless steel, equipped with a mechanical stirrer, heating mantle, cooling coil, and automatic dosing of ethylene oxide, and measurement and control equipment controlled by computer. Hydrophobic substrate was mixed with a predetermined amount of the catalyst and fed into the reactor. This was mixed with the desired amount of the catalyst $(0.1$ wt. $\%$ of $\mathrm{NaOH}$ and 0.25 wt. $\%$ of calcium catalyst calculated on the product weight, respectively) and placed in the reactor. After loading the reactor and checking the tightness of the raw material, the charge was dried at $130^{\circ} \mathrm{C}$ under an atmosphere of nitrogen for 30 minutes to remove traces of water. Then the reactor temperature was raised to the desired reaction temperature and we started the automatic dosing of ethylene oxide. The reaction was carried out at $160^{\circ} \mathrm{C}$ in the presence of $\mathrm{NaOH}$ and at $185^{\circ} \mathrm{C}$ in the presence of calcium catalyst, until a desired amount of ethylene oxide was introduced. After the introduction of predetermined amounts of ethylene oxide the reaction mixture was post-cured for a further 50 minutes at the reaction temperature in order to maximize reaction substrates. After cooling to about $60^{\circ} \mathrm{C}$ the reactor was purged with nitrogen, and the product was discharged, weighed, and subjected to the required analysis.

Analytical Methods

\section{Determining Fractional Content of Ethoxylates}

Gas chromatography was applied to determine the homologue distribution of the directly ethoxylated fatty acid methyl esters and ethoxylateddodecanol. The ethoxylated methyl esters were determined as they appear originally, without any derivatization, while dodecanolethoxylates were analysed as acetate derivatives. The investigated samples were diluted in benzene prior to analysis and the solution was injected into the chromatograph. The ratio of benzene to the ethoxylate sample was 10:1. Analyses were performed using a Hewlett Packard chromatograph, model 5890 series 2, using a DB-2HT column (Alltech Associates Inc.), $10 \mathrm{~m}$ long and $0.32 \mathrm{~mm}$ in diameter with film thickness of $0.1 \mu \mathrm{m}$. The separation temperature was programmed from 60 up to $340^{\circ} \mathrm{C}$ and the detector temperature was $360^{\circ} \mathrm{C}$.

\section{Determining Cloud Point in Butyl Diglycol Ether $\left(C p_{(B D G)}\right)$}

Cloud point in butyl di-glycol ether $\left(\mathrm{Cp}_{(\mathrm{BDG})}\right)$ was determined according to the ISO 1065 Standard by diluting $5.00 \mathrm{~g}$ of surfactant in $45 \mathrm{~g}$ of an aqueous $25 \%$ $(\mathrm{m} / \mathrm{m})$ solution of n-butyl-diethylene glycol. The final solution was heated until completely opaque and next allowed cooling down while stirring. The temperature at which opacity disappeared was marked as the cloud point. 


\section{Determining Cloud Point in Water $\left(\mathrm{Cp}_{(\mathrm{H} 2 \mathrm{O})}\right)$}

Cloud point in water $\left(\mathrm{Cp}_{(\mathrm{H} 2 \mathrm{O})}\right)$ solution was determined in the same way as above, with the exception of $1 \%(\mathrm{~m} / \mathrm{m})$ of surfactant in distilled water.

\section{Aquatic Toxicity Tests}

Aquatic toxicity tests were performed in Poland in the Ecotoxicological Laboratory Institute of Industrial Organic Chemistry in Pszczyna. The tests were performed according to the OECD Guidelines for Testing of Chemicals Procedure No. 202: "Daphnia sp., Acute Immobilisation Test and Reproduction Test," Part I - the 48-hour $\mathrm{EC}_{50}$ acute immobilization test; and Procedure No. 203: "Fish, Acute Toxicity Test" - the 96-hour $\mathrm{LC}_{50}$ test procedure [21-22].

\section{Biodegradability Tests}

Biodegradability tests were performed on active sludge following the OECD Confirmatory Test procedure No. 82/242/EEC, at the certified biodegradable laboratory of the Blachownia Institute of Heavy Organic Synthesis in Kędzierzyn-Koźle according to Council Directive 82/242/ EEC of 31 March 1982 on the approximation of the laws of the member states relating to methods of testing the biodegradability of non-ionic surfactants and amending Directive 73/404/EEC [23].

\section{Results and Discussion}

In this study of series of ethoxylated dodecanol and ethoxylated rapeseed acid methyl esters, of average degree of ethylene oxide addition $\left(\mathrm{N}_{\mathrm{av}}\right)$ equal to 5, 7, 9, 12, and 15 were used. The chemical structures of surfactants are presented in Fig. 1.

a)
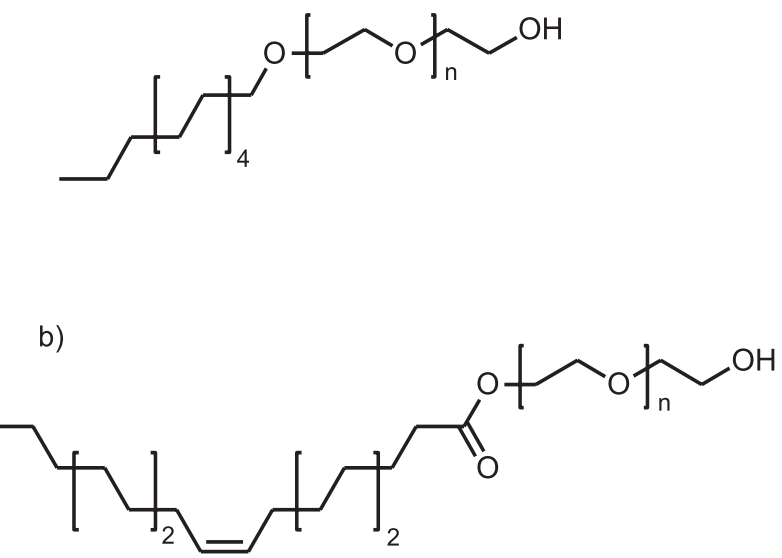

Fig. 1. Chemical structures of ethoxylated 1-dodecanol a) ethoxylated oleic acid methyl ester (the main component of rapeseed acid methyl esters) b) used in our study.

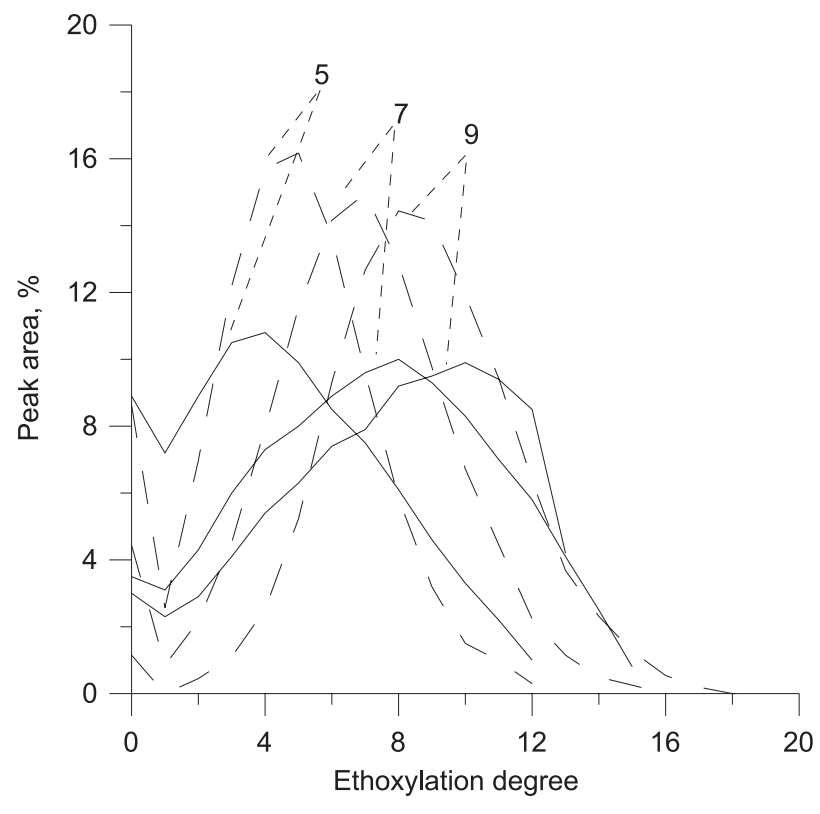

Fig. 2. Comparison of fractional composition of ethoxylated dodecanol (solid line) and ethoxylated rapeseed acid methyl esters (dashed line) for products of average polyaddition degree equal to 5,7 , and 9 , respectively.

Fractional compositions of the compared series of surfactants are presented in Fig. 2.

Fractional composition of the products of average degree of ethylene oxide addition $\mathrm{N}_{\mathrm{av}}=12$ and $\mathrm{N}_{\mathrm{av}}=15$ are not shown in Fig. 1 because of too high molecular weight and not enough accurate quantitative determination by means of the available chromatographic techniques. However, it can be observed that the ethoxylated methyl esters exhibit narrower homologue distributions compared to those of their fatty alcohol equivalents obtained with a conventional alkaline catalyst. A comparative physicochemical characteristic of the both studied types of ethoxylates is presented in Table 1.

The solubility of ethoxylated rapeseed esters in water is relatively lower compared to that of ethoxylated 1-dodecanol at the equivalent polyaddition degrees $\left(\mathrm{N}_{\mathrm{av}}\right)$. This results from a higher molecular weight of the hydrophobe chain and thus relatively lower hydrophilic lipophilic balance of ethoxylated rapeseed acid methyl esters. The percentage of biological degradation of the studied surfactants was measured daily, based on its concentration measured as biological active substance (BiAS, mg/l) at the system inlet-outlet, following the active sludge method and the OECD confirmatory test procedure. The result of biodegradation, expressed as a percentage, was calculated as the average value from 14 measurements where the initial surfactant concentration was established at $10.0 \mathrm{mg} / \mathrm{l}$. The results are presented in Fig. 3.

The results indicate biodegradation determined above the obligatory level of $80 \%$ in each case. The higher the average poly addition degree, the lower the primary degradation (although somewhat faster removal of the 
Table 1. Refraction index $\left(\mathrm{n}^{\mathrm{D}}{ }_{20}\right)$ and cloud points in water $\left(\mathrm{Cp}_{(\mathrm{H} 2 \mathrm{O})}\right)$ and in butyl diglycol solution $\left(\mathrm{Cp}_{(\mathrm{BDG})}\right)$ of ethoxylated dodecanol and ethoxylated rapeseed acid methyl esters in relation to $\mathrm{N}_{\mathrm{av}}$ parameters.

\begin{tabular}{|c|c|c|c|c|c|c|}
\hline \multirow{2}{*}{$\mathrm{N}_{\mathrm{av}}$} & $\mathrm{n}_{20}^{\mathrm{D}}$ & $\mathrm{Cp}_{(\mathrm{H} 2 \mathrm{O})}$ & $\mathrm{Cp}_{(\mathrm{BDG})}$ & $\mathrm{n}^{\mathrm{D}}{ }_{20}$ & $\mathrm{Cp}_{(\mathrm{H} 2 \mathrm{O})}$ & $\mathrm{Cp}_{(\mathrm{BDG})}$ \\
\hline & \multicolumn{3}{|c|}{ Ethoxylated1-dodecanol } & \multicolumn{3}{|c|}{ Ethoxylated fatty acid methyl ester } \\
\hline 5 & 1.4480 & 50.0 & 71,0 & 1.4540 & cloudy & 54.0 \\
\hline 7 & 1.4510 & 51.0 & 79,5 & 1.4550 & cloudy & 61.0 \\
\hline 9 & 1.4523 & 55.0 & 84,0 & 1.4560 & 40.5 & 66.0 \\
\hline 12 & 1,4537 & 57.2 & 87,0 & 1.4580 & 58.0 & 72.0 \\
\hline 15 & 1.4542 & 59.3 & 89,5 & 1.4590 & 72.5 & 74.0 \\
\hline
\end{tabular}

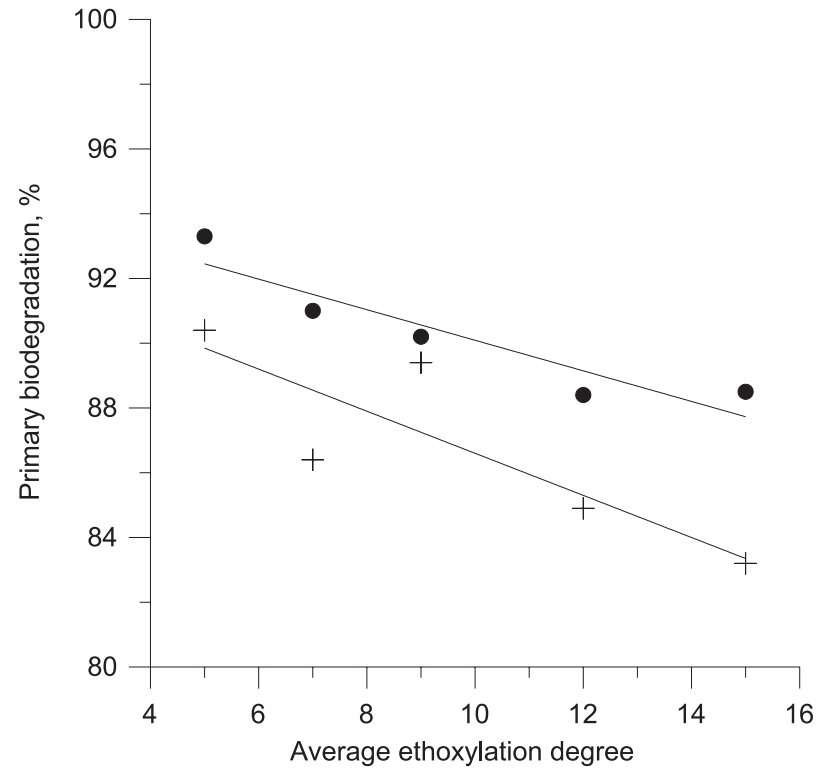

Fig. 3.Comparative studies of primary biodegradation of ethoxylated dodecanol $(+)$ and ethoxylated rapeseed acid methyl esters $(\bullet)$ as determined by the active sludge OECD confirmatory test procedure, in relationship to average poly addition degree.

active substance was observed in the case of ethoxylated rapeseed acid methyl esters). However, it is also important to recognize the toxicological interaction of the surfactants against water organisms. For that purpose two model 48-96 hour acute toxicity tests against fish $\left(\mathrm{LC}_{50}\right)$ and Daphnia sp. $\left(\mathrm{EC}_{50}\right)$ were performed. Based on the obtained test results a standard OECD classification is specified depending on the $\mathrm{LC}_{50}$ or $\mathrm{EC}_{50}$ determinations (Table 2) [20, 23].

Table 2. Classification of toxicity against water organisms based on $\mathrm{EC}_{50}$ and $\mathrm{LC}_{50}$ determinations.

\begin{tabular}{|c|c|c|}
\hline Toxicity class & Symbol & $\begin{array}{c}\text { Values } \\
\mathrm{LC}_{50 / 96 \mathrm{~h}} / \mathrm{EC}_{5048 \mathrm{~h}}, \mathrm{mg} / 1\end{array}$ \\
\hline Very toxic & $\mathrm{R} 50$ & $\mathrm{LC}_{50} / \mathrm{EC}_{50}<1$ \\
\hline Toxic & $\mathrm{R} 51$ & $1<\mathrm{LC}_{50} / \mathrm{EC}_{50}<10$ \\
\hline Harmful & R 52 & $10<\mathrm{LC}_{50} / \mathrm{EC}_{50}<100$ \\
\hline
\end{tabular}

Acute toxicity $\mathrm{LC}_{50}$ and $\mathrm{EC}_{50}$ exhibited by surfactants typically range from $0.25 \mathrm{mg} / \mathrm{l}$ up to $150 \mathrm{mg} / \mathrm{l}$ and from $0.1 \mathrm{mg} / \mathrm{l}$ to $250 \mathrm{mg} / \mathrm{l}$ for fish and Daphnia, respectively, although Daphnia are usually more sensitive to surfactants compared to fish. Generally, the measured toxicity decreased gradually along the increasing average poly addition degrees. As was expected, in all cases the investigated surfactants were more toxic for Daphnia than for fish. The measured acute toxicity of the studied series of dodecanolethoxylates varied from $3.11 \mathrm{mg} / 1$ up to $20.4 \mathrm{mg} / 1$ for Daphnia magna $\left(\mathrm{EC}_{50 / 48 \mathrm{~h}}\right)$, and from $7.48 \mathrm{mg} / \mathrm{l}$ up to $45.8 \mathrm{mg} / 1$ for Lebistesreticulatus $\left(\mathrm{LC}_{50 / 96 \mathrm{~h}}\right)$. Respectively lower toxicity against water organisms was determined for the studied series of ethoxylated rapeseed oil acid methyl esters, where $\mathrm{EC}_{50 / 48 \mathrm{~h}}$ was measured in the range from $22.1 \mathrm{mg} / \mathrm{l}$ up to $40.8 \mathrm{mg} / \mathrm{l}$, and $\mathrm{LC}_{50 / 96 \mathrm{~h}}$ ranged from $30.6 \mathrm{mg} / \mathrm{l}$ up.

Following the obtained results, and according to European Union Directive No. 67/548/EEC with respective amendment No. 7, dodecanolethoxylates of $\mathrm{n}_{\mathrm{av} .},<12$ are classified to the second toxicity class (R51, regarded as toxic against water organisms), while the others of higher average poly addition degrees are specified as to the third toxicity class (R52, marked as harmful) [24, 25]. Whereas ethoxylated rapeseed acid methyl esters were classified to the third toxicity class according to the test on Daphnia magna and, with one exception, they fall out of the classification of EU regarding toxicity against water organisms, as determined on fish. Generally it can be stated that aquatic toxicity of ethoxylated rapeseed acid methyl esters was found to be an order lower compared to that of ethoxylated fatty alcohols. This might be caused by the methoxy group at the end of the polyoxyethylene chain, which prevents penetration of the surfactant molecules through cellular walls and/or mucous membranes. Such speculation could also be supported by the fact that ethoxylated rapeseed acids methyl esters showed no allergic action toward human skin, contrary to the other surfactants [8]. Our further studies have proved that, compared to ethoxylated fatty alcohols, ethoxylated rapeseed acid methyl esters have shown significantly less or no irritation to skin and eye, as tested on rabbits.

For a comprehensive evaluation of the potential environmental fate of surfactants it is necessary to consider combined data from bidoegradation and aquatic toxicity, 
Table 3. Prognostic concentrations of nonionic surfactants in municipal wastewater and their environmental fate in terms of aquatic toxicity for alternative applications of ethoxylated dodecanol and oxyethylated rapeseed acid methyl etsters in relationship to average polyaddition degree, as simulated for the region of Warsaw.

\begin{tabular}{|c|c|c|c|c|c|c|}
\hline $\mathrm{N}_{\mathrm{av} .}$ & $\begin{array}{c}\text { Biodegradation } \\
\%\end{array}$ & $\mathrm{Ke}, \mathrm{mg} / \mathrm{l}$ & $\begin{array}{l}\text { Daphnia magna, } \\
\text { EC }_{50 / 48 \mathrm{~h}}, \mathrm{mg} / 1\end{array}$ & $\mathrm{EC}_{50} / \mathrm{Ke}$ & $\begin{array}{l}\text { Lebistes reticulatus } \\
\mathrm{LC}_{50 / 96 \mathrm{~h}}, \mathrm{mg} / 1\end{array}$ & $\mathrm{LC}_{50} / \mathrm{Ke}$ \\
\hline \multicolumn{7}{|c|}{ ethoxylate 1-dodecanol } \\
\hline 5 & 90.4 & 0.057 & 3.11 (toxic) & 54.6 & 7.5 (toxic) & 131.6 \\
\hline 7 & 86.4 & 0.069 & 8.77 (toxic) & 127.1 & 7.5 (toxic) & 108.7 \\
\hline 9 & 89.4 & 0.071 & 9.82 (toxic) & 138.3 & 18.3 (harmful) & 257.7 \\
\hline 12 & 84.9 & 0.096 & 15.61 (harmful) & 162.6 & 28.7 (harmful) & 299.0 \\
\hline 15 & 83.2 & 0.104 & 20.4 (harmful) & 196.2 & 40.5 (harmful) & 389.4 \\
\hline \multicolumn{7}{|c|}{ Ethoxylate rapeseed acid methyl ester } \\
\hline 5 & 93.3 & 0.047 & 22.1 (harmful) & 470.2 & $>100$ (safe) & $2,127.7$ \\
\hline 7 & 91.0 & 0.063 & 25.4 (harmful) & 403.2 & $>100$ (safe) & 158.3 \\
\hline 9 & 9,2 & 0.068 & 30.2 (harmful) & 444.1 & 40.6 (harmful) & 597.1 \\
\hline 12 & 88.4 & 0.081 & 35.7 (harmful) & 440.7 & $>100$ (safe) & $1,234.6$ \\
\hline 15 & 88.5 & 0.080 & 40.8 (harmful) & 510.0 & $>100$ (safe) & $1,250.0$ \\
\hline
\end{tabular}

taking into account their concentration in the natural environment. For that purpose an average consumption per capita of surfactants should be estimated in certain areas. An additional assumption is made that total amounts of the consumed surfactants are wasted.

From the amounts of consumed water and surfactants at any considered area and taking into account their biodegradability, one can estimate permanent concentration of the surfactants existing in the wasted streams. As a result, it is possible to classify toxicity of the investigated chemical load in the environment. The following formula allows calculation of the prognostic concentration of a given surfactant in wasted water $\left(\mathrm{K}_{\mathrm{e}}\right.$, $\mathrm{mg} / \mathrm{l})$ [26]:

$$
\mathrm{Ke}=\frac{\mathrm{P} \cdot \mathrm{M} \cdot 10^{6}}{\mathrm{MQ} \times 1000} \cdot \frac{100-\mathrm{A}}{100}
$$

...where $\mathrm{P}$ is population at the considered area, $\mathrm{M}$ is quantity of surfactant consumed per capita on the considered area $(\mathrm{kg} / \mathrm{y}), \mathrm{A}$ is the decrease of surfactant concentration as the result of its biodegradation (BiAS, \%), and MQ is average yearly flow of water stream at the considered area $\left(\mathrm{m}^{3} / \mathrm{y}\right)$.

For ecological safety, it is further assumed that the theoretically calculated concentration of surfactant in natural environment should be 100 times lower than the values of $\mathrm{LC}_{50}$ and $\mathrm{EC}_{50}$ determined experimentally. In such a case, no negative environmental impact of the subject surfactant could be expected. The obtained results of toxicity are typically much higher compared to what could be found in the environment. But at least they indicate the worst possible scenario. The discussed theoretical model only approximates a potential danger for the surface water by individual assortments of surfactants. Additionally, it clearly depicts any differences between the individual surfactant types regarding their action against the natural environment.

An exemplary prognostic model for environmental impact of the studied series of surfactants was developed for the region of Warsaw, where the population of 1.6 million consumes an average water stream equal to $2.3 * 10^{9} \mathrm{~m}^{3}$ per year [26-28]. Additionally, an average yearly consumption of surfactant was assumed as $1 \mathrm{~kg}$ per capita. As a result, the prognostic concentrations $(\mathrm{Ke})$ of dodecanolethoxylates and, alternatively, rapeseed acid methyl ester ethoxylates, as well as the ratios of the theoretical prognostic concentrations and the respective $\mathrm{EC}_{50}$ and $\mathrm{LC}_{50}$ concentrations, are presented in Table 3.

We can observe that the expected environmental fate of ethoxylated rapeseed acid methyl esters is a few times lower compared to that of ethoxylateddodecanol. Furthermore, at lower average poly addition degrees fatty alcohol ethoxylates could even be regarded as dangerous $\left(\mathrm{EC}_{50} / \mathrm{Ke}<100\right)$ in terms of their long-term action toward water organisms.

In this context, for example, the environmental impact of dodecanolethoxylate of the average poly addition degree equal to 5 could be directly related to that of ethoxylated rapeseed acid methyl ester of average poly addition degree equal to 9 . These surfactants represent alternative nonionic ingredients dedicated to the application in washing formulations, consuming the major part of surfactants manufactured worldwide. Based on the results of biodegradation and toxicity tests for Daphnia magna, the prognostic model developed for the region of Warsaw indicates a ratio of $\mathrm{EC}_{50} / \mathrm{Ke}$ as equal to 60 and 440 for the 
compared surfactants, respectively. This shows that the replacement of ethoxylateddodecanol by its ethoxylated rapeseed acid methyl ester equivalent can decrease the expected risk of negative environmental impact by seven times.

\section{Conclusions}

Based on the results from comparative measurements of biodegradability and aquatic toxicity it can be stated that ethoxylated rapeseed acid methyl esters represent environmentally superior surfactants. They exhibit relatively higher biodegradation and lower toxicity againstwaterorganisms compared tododecanolethoxylates. The developed model of prognostic analysis of environmental evaluation of the compared surfactant series indicates an ecological risk of bulk application of dodecanolethoxylates, while a significant reduction of environmental fate would occur by the alternative use of ethoxylated rapeseed acid methyl esters. As a result, the development of production and application of the alternative surfactant lies in line with a good understanding of environmental protection.

\section{Acknowledgements}

This work was financed and carried out within the statutory tasks realized by the ICSO "Blachownia".

\section{References}

1. ROMSTED LAURENCE S. Surfactants Science and Technology: Retrospects and Prospects, CRC Press Taylor\&Fracis Group, Boca Raton, 2014.

2. SUŁEK M., QIU XIAO L., YONGQIANG S., HRECZUCH W. Global economic trends in the surfactans sector, Przemysł Chemiczny 89, 1316, 2010 [In Polish].

3. SRIRAM P., SMITH K., KEEL T. Chemical Economics Handbook Ethylene Oxide, IHS Chemical; May 2013.

4. Polish market of washing agents, Chemia i Biznes. Rynek Kosmetyczny i Chemii Gospodarczej 54, 2/2016 [In Polish].

5. TIEDKE E., OTTO K., BLICKENSTORFER CH. Nonionic surfactants as process chemicals for the paper industry, Wochenblatt fur Papierfabrikation, 138 (11), 890, 2010.

6. COX M.F., WEERASOORIYA U. Methyl Ester Ethoxylates, J. Am. Oil Chem. Soc. 74 (7), 847, 1997

7. LITTAU C., MILlER D. Optimization of Surfactant Systems Containing Methyl Ester Ethoxylates, SÖFWJournal,124, 690, 1998

8. BIAŁOWAZS E., SZYMANOWSKI J. Catalysts for Oxyethylation of Alcohols and Fatty Acid Methyl Esters; Ind. Eng. Chem. Res. 43, 6267, 2004.

9. ALEJSKI K., EMMONS M., LUKOSEK M., MIESIĄC I. Fatty acids methyl esters ethoxylation on heterogeneous catalyst. Experimental tests and process modeling, Inżynieria i Aparatura Chemiczna,3, 17, 2010 [In Polish].

10. ZHANG Q., SUN Y., ZHI L., ZHANG Y., DI SERIO M. Properties of ethoxylated castor oil acid methyl esters pre- pared by ethoxylation over an alkaline catalyst, Journal of Surfactants and Detergents, 18 (2) 365, 2015.

11. HRECZUCH W. Ethoxylated Rape Oil Acid Methyl Esters as New Ingredients for Detergent Formulations, Tenside Surf. Deterg. 38 (1), 72, 2001.

12. GAUVRIT C., MUELlER T., MILIUS A., TROUVE G. Ethoxylated rapeseed oil derivatives as non-ionic adjuvants for glyphosate, Pest Management Science, 63 (7) 707, 2007.

13. SUŁEK M., KULCZYCKI A., MAŁYSA A. Assessment of lubricity of compositions of fuel oil with biocomponents derived from rapeseed, Wear 268, 104, 2010.

14. SUŁEK M., BĄK-SOWIŃSKA A. Sunflower oil ethoxylates aquaeous solutions as effective bases for lubricating substances; Przemysł Chemiczny 92/8, 1506, 2013 [In Polish].

15. ZGODA M.M., WOSKOWIC Z M., NACHAJSKI M., KOŁODZIEJCZYK MICHA $Ł$ K., LUKOSEK M., JERZYKIEWICZ W. Surfactants from polyethoxylated fatty acids esters group; Polimery 50 (11-12), 873, 2005 [In Polish].

16. PIOTROWSKA J.B., NACHAJSKI M.J., LUKOSEK M. KOSNO J., ZGODA M.M. Surfactants from polyethoxylated fatty acids esters with glycerin group; Polimery w Medycynie 41 (1), 53, 2011 [In Polish].

17.http://www.ihs.com/products/chemical/planning/world-petro-analysis/ethylene-oxide-glycol.aspx?pu=1\&rd=chemihs; (09-2012).

18. BLAGOJEVIC S.N., BLAGOJEVIC S.M., PEJIC N.D. Performance and Efficiency of Anionic Dishwashing Liquids with Amphoteric and Nonionic Surfactants, Journal of Surfactants and Detergents, 19 (2) 363, 2016.

19. OECD Guidelines for the Testing of Chemicals. No 202 Daphnia sp., Acute immobilisation Test and Reproduction Test, Part I - the $24 \mathrm{~h}$ EC 50 acute immobilisation test. Paris, $1,1993$.

20. Regulation (EC) No 648/2004 of the European Parliament and of the Councilof 31 March 2004 on detergents (published in Official Journal L 104, P. $0001-0035,8^{\text {th }}$ April 2004) [In Polish].

21. OECD Guidelines for the Testing of Chemicals No. 203,Fish, Acute Toxicity Test. Paris, 1, 1993.

22. Council Directive 82/242/EEC of 31 March 1982 on the approximation of the laws of the Member States relating to methods of testing the biodegrability of non-ionic surfactants and amending Directive 73/404/EEC.

23. European Communities, Seven Amending. To Directive 67/548/EEC. 1992. Classification of packages and labelling of danger substances.

24. SCHOEBERL P, BOCK K., LUDWIG H. Ecological data for surface active substance in washing and cleaning agents, Minheim, Germany, 1987.

25. ZIELIŃSKI R. Surfactants structure, properties, applications; Wydawnictwo Uniwersytetu Ekonomicznego w Poznaniu, Poznań 2013 [In Polish].

26. SZWACH I. The influence of fractional composition of ethocylated fatty alcohols on the assessment of their ecological impact. Przem. Chem, 81 (7), 454, 2002 [In Polish].

27. SZWACH I., HRECZUCH W. Comparative studies of biodegradation and ethoxylation of alcohols with narrow and wide homologue distribution. Przem.Chem. 81 (8), 522, 2002 [In Polish].

28. RENKIN M., FLEURACKERS S., SZWACH I., HRECZUCH W. Rapeseed methyl ester ethoxylates: A new class of surfactants of environmental and commercialinterest. Tenside Surf. Deterg. 42 (5) 280, 2005. 